\title{
Rapid Detection of HLA-B*57:01-Expressing Cells Using a Label-Free Interdigitated Electrode Biosensor Platform for Prevention of Abacavir Hypersensitivity in HIV Treatment
}

\author{
Jianxiong Chan ${ }^{1, \dagger}{ }^{\text {, Gita V. Soraya }}{ }^{1,2,+}{ }^{+}$, Lauren Craig ${ }^{1}$, Shah M. Uddin ${ }^{1}$, Marian Todaro ${ }^{1,3}$, \\ Duc H. Huynh ${ }^{4}$, Chathurika D. Abeyrathne ${ }^{4}$, Lyudmila Kostenko ${ }^{5}$, James McCluskey ${ }^{5}$, \\ Efstratios Skafidas ${ }^{4}$ and Patrick Kwan 1,3,* \\ 1 Department of Medicine, Royal Melbourne Hospital, The University of Melbourne, Victoria 3050, Australia \\ 2 Department of Biochemistry, Faculty of Medicine, Hasanuddin University, Makassar 90245, Indonesia \\ Department of Neurology, Royal Melbourne Hospital, Victoria 3050, Australia \\ 4 Department of Electrical and Electronic Engineering, Melbourne School of Engineering, The University of \\ Melbourne, Victoria 3010, Australia \\ 5 Department of Microbiology and Immunology, The Peter Doherty Institute for Infection and Immunity, \\ The University of Melbourne, Victoria 3010, Australia \\ * Correspondence: patrick.kwan@unimelb.edu.au \\ $\dagger$ These authors made equal contribution.
}

Received: 4 July 2019; Accepted: 11 August 2019; Published: 14 August 2019

\begin{abstract}
Pre-treatment screening of individuals for human leukocyte antigens (HLA) HLA-B*57:01 is recommended for the prevention of life-threatening hypersensitivity reactions to abacavir, a drug widely prescribed for HIV treatment. However, the implementation of screening in clinical practice is hindered by the slow turnaround time and high cost of conventional HLA genotyping methods. We have developed a biosensor platform using interdigitated electrode (IDE) functionalized with a monoclonal antibody to detect cells expressing HLA-B*57:01. This platform was evaluated using cell lines and peripheral blood mononuclear cells expressing different HLA-B alleles. The functionalized IDE sensor was able to specifically capture HLA-B*57:01 cells, resulting in a significant change in the impedance magnitude in $20 \mathrm{~min}$. This IDE platform has the potential to be further developed to enable point-of-care HLA-B*57:01 screening.
\end{abstract}

Keywords: human leukocyte antigen; interdigitated electrodes; impedance sensor; protein sensor; point-of-care diagnostics; pharmacogenetics

\section{Introduction}

Adverse drug reactions (ADRs) account for more than 700,000 injuries or deaths per year in the United State alone [1]. Recent pharmacogenetics research has identified associations between the human leukocyte antigens (HLA) encoded by the major histocompatibility complex (MHC) gene family and ADRs. These immune-mediated ADRs manifest as cutaneous reactions which range from minor maculopapular exanthema to severe reactions such as Stevens Johnson syndrome (SJS), toxic epidermal necrolysis (TEN), and drug-induced hypersensitivity syndrome (DIHS). These severe reactions carry mortality rates of up to $30 \%$ [2]. The MHC gene family is a highly polymorphic region in the human genome and is known for its role in immune response and various disease processes. A high level of variations is found within the Class I HLA region, which encompasses the HLA-A, HLA-B, and HLA-C genes. There are currently 12,544 allele sequences within Class I recorded in the International Immunogenetics (IMGT)/HLA database, of which 4828 belong to the HLA-B group [3]. 
A prime example of such pharmacogenetic association is the strong relationship between HLA-B*57:01 and a hypersensitivity reaction to abacavir [4-7]. This association appears to be strictly linked to HLA-B*57:01 and not to other closely related HLA allotypes [8,9]. Abacavir is widely prescribed for HIV treatment, but approximately $5 \%$ of patients develop hypersensitivity reactions [5]. The most common symptoms are fever, rash, fatigue and nausea or vomiting, while respiratory and cardiac symptoms have also been reported [5]. HLA testing prior to abacavir administration is recommended by the U.S. Food and Drug Administration (FDA) and is supported by expert opinions [10-13].

HLA-B*57:01 is traditionally detected by DNA-based methods such as polymerase chain reaction (PCR) and sequence-based typing. These laboratory-based methods are time consuming and costly, which impair the implementation of HLA testing [14-16]. This delay is also impractical when a treatment decision is preferred to be made instantaneously for optimal care or in resource-poor environments.

Our group has previously developed a monoclonal antibody (mAb), known as 3E12, capable of recognizing members of the HLA-B17 group, including HLA-B*57:01 [17]. The sensitivity and specificity of this antibody was demonstrated in three independent laboratories using flow cytometry [17]. In those studies, it was shown that patients who tested negative by mAb screening comprised $90-95 \%$ of all individuals in most ethnic populations and required no further HLA typing [17]. This mAb screening may provide a low-cost alternative to high-resolution typing of all patients and rapid ascertainment of low-risk patients who can begin immediate therapy with abacavir.

The present study aimed to develop this $\mathrm{mAb}$ from a laboratory-based application towards a biosensor platform. We combined the selectivity of this $\mathrm{mAb}$ with sensitivity of biosensor, setting the basis for future point-of-care application. Biosensors are promising options due to their high sensitivity, low cost, and amenability to miniaturisation. Through a point-of-care application, samples would not need to be sent to distant laboratories, greatly reducing the time and cost for HLA-B*57:01 screening.

\section{Materials and Methods}

\subsection{Overall Design}

The central design of the platform comprises of an interdigitated electrode (IDE) sensor functionalized with an antibody targeting against specific cell surface protein. The IDE sensors were fabricated via UV lithography at low cost and have previously demonstrated sensitivity for label-free detection of various biomolecules [18-22].

For HLA-B*57:01 cell detection, the mAb 3E12 was immobilized on the IDE sensor surface. Cell overexpressing HLA-B*57:01 protein on the surface bound to 3E12 on the sensor. The binding of cells to the antibody resulted in changes in signal impedance of the IDE sensor. The changes in signal impedance were detected by a lock-in amplifier (Figure 1).

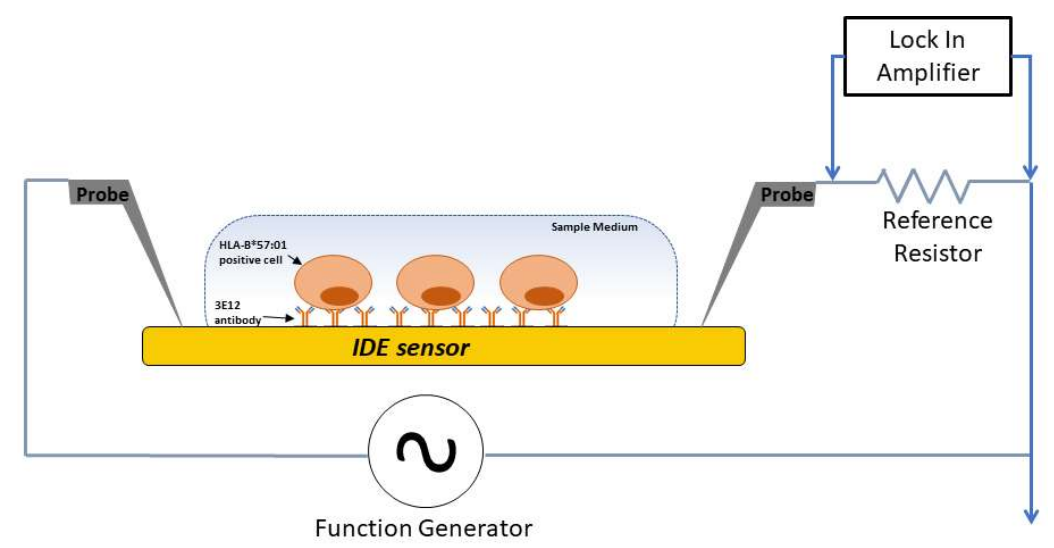

Figure 1. Circuit model and measurement setup used for detection of HLA-B*57:01 cell capture. 
A cross-sectional view of the measurement setup illustrates detection of captured HLA-B*57:01 cells in a sample medium with the sensing area. Probe electrodes were placed to deliver excitation current to and to measure electrical signals from the sensors.

There were two experimental stages in this study. Stage I involved proof-of-concept experiments followed by optimisation of the experimental parameters using cultured cell lines with and without HLA-B*57:01 expression. The cell capture conditions were optimized on a glass surface followed by signal characterisation of the capture on an IDE sensor. The parameters developed in stage I were evaluated in stage II using human peripheral blood mononuclear cells (PBMC) of known HLA genotypes. The study was approved by The University of Melbourne ethics committee (ethics ID 1443204.4).

\subsection{Samples}

\subsubsection{Cell Lines}

Human lymphoblastoid HLA Class I-reduced cell lines (C1R) overexpressing HLA-B*57:01 or HLA-B*15:02, were cultured in Roswell Park Memorial Institute (RPMI) media (Thermo Fisher Scientific, MA, USA) supplemented with $2 \mathrm{mM}$ Minimum Essential Medium (MEM) non-essential amino acid solution (Thermo Fisher), $100 \mathrm{mM}$ (4-(2-hydroxyethyl)-1-piperazineethanesulfonic acid (HEPES) (ICN Biochemicals, Aurora, OH, USA), 2 mM L-glutamine (Merck, Darmstadt, Germany), 0.6 mg/L benzylpenicillin (CSL, Melbourne, Australia), $1 \mathrm{mg} / \mathrm{L}$ streptomycin (CSL), $50 \mu \mathrm{M}$ 2-mercaptoethanol (Merck) and 10\% FBS (CSL, Melbourne) with 1\% G418 selection antibiotic (Thermo Fisher) and were kept in humid conditions at $37^{\circ} \mathrm{C}, 5 \% \mathrm{CO}_{2}$.

\subsubsection{Isolated PBMC Samples}

PBMCs were prepared from blood samples of healthy donors and isolated via the standard Ficoll-Paque and density-gradient centrifugation method. Isolated cells were stored in liquid nitrogen until use. Samples were rapidly thawed with RPMI media, pelleted and supernatant removed. Cells were resuspended in RPMI (10\% FCS) and kept in humid conditions at $37^{\circ} \mathrm{C}, 5 \% \mathrm{CO}_{2}$.

\subsection{Antibody}

The $\mathrm{mAb}, 3 \mathrm{E} 12$, was functionalized on glass and an IDE sensor. The antibody was previously produced by our group [17] against the HLA-B17 serotype, which comprises of $B * 57: 01$ and $B * 58: 01$.

\subsection{Functionalization of Glass Surface}

To attach the 3E12 antibody, the glass slides were first cleaned with ethanol and acetone at a 50:50 ratio, sonicated for $5 \mathrm{~min}$ and air dried. Slides were incubated for $1 \mathrm{~h}$ in $2 \%$ (3-aminopropyl) triethoxysilane (APTES) (Merck) in 95\% ethanol, washed in 1\% Phosphate Buffered Solution (PBS) and incubated in $2.5 \%$ glutaraldehyde (Merck) in distilled water for $2 \mathrm{~h}$. Following incubation, the slides were washed in distilled water and the antibodies were immobilized at $100 \mu \mathrm{g} / \mathrm{mL}$ on the surface overnight at $4{ }^{\circ} \mathrm{C}$. After incubation, the slides were washed with PBS and incubated for $1 \mathrm{~h}$ in $1 \%$ ethanolamine. Finally, the slides were washed and kept in PBS.

\subsection{Fabrication and Functionalization of IDE Sensor}

\subsubsection{Sensor Fabrication}

The IDE sensors were fabricated at the Melbourne Centre for Nanofabrication (Clayton, Victoria, Australia) using UV-lithography on BOROFLOAT glass wafers [18-21]. Each IDE sensor consisted of paired electrode arrays with a finger length of $980 \mu \mathrm{m}$, a finger width of $8 \mu \mathrm{m}$ and a gap width of $8 \mu \mathrm{m}$. An additional level of $\mathrm{SiO}_{2}$ ( $25 \mathrm{~nm}$ thickness) was deposited through e-beam evaporation. 


\subsubsection{Sensor Functionalization}

The fabricated sensors were washed with acetone, isopropyl alcohol and $\mathrm{H}_{2} \mathrm{O}$, and dried under nitrogen gas. Sensors were then plasma treated (PE-25 Plasma Etch, NV, USA) with argon (75\%) and oxygen ( $25 \%$ ) for $5 \mathrm{~min}$ at $50 \mathrm{~W}$ power, and $30 \mathrm{cc} / \mathrm{min}$ flow rate. The sensors were then functionalized in accordance to our established protocols [18-21]. Briefly, sensors were incubated in filtered (Corning ${ }^{\circledR}$ $0.2 \mu \mathrm{m}) 2 \%$ APTES in ethanol solution for $1 \mathrm{~h}$, followed by $3 \times 5$ min washes in $100 \%$ ethanol with gentle shaking. Sensors were then incubated in filtered $2.5 \%$ glutaraldehyde solution for $2 \mathrm{~h}$, followed by $3 \times 5$ min wash in PBS with gentle shaking and dried under nitrogen gas. Antibodies were then incubated on sensing area at $100 \mu \mathrm{g} / \mathrm{mL}$ at $4{ }^{\circ} \mathrm{C}$ overnight. After incubation, the slides were washed with PBS and incubated for $1 \mathrm{~h}$ in $1 \%$ ethanolamine before washed and stored in PBS.

\subsection{Cell Capture Assay}

The cell lines or PBMCs, depending on experimental stages, were incubated at 160 cells $/ \mu \mathrm{L}$ in a glass or sensor surface in their respective culture media at $37^{\circ} \mathrm{C}$. After the applicable incubation time, the slides or sensors were washed three times in PBS and counted under a microscope in PBS.

\subsection{Cell Counting}

Images of slides or sensors with captured cells were taken at 50× magnification by inverted microscope using Axio Image software. Cell counts were performed on an area of $0.5 \mathrm{~mm}^{2}$ using ImageJ software, utilizing threshold adjustment and article analysis tools.

\subsection{Electrical Measurement}

Impedance of the sensors was measured using established circuit setup [18-21], in which the sensor, represented as a resistor $(\mathrm{R})$, was in a series with a capacitor $(C)$ connected in series with a $1 \mathrm{k} \Omega$ reference resistor $\left(R_{r e f}\right)$. The input sinusoidal AC excitatory signal $\left(V_{i n}\right)$ was provided by a function generator at $20 \mathrm{mV}$ peak-to-peak voltage $\left(V_{p p}\right)$ using different frequencies $(10 \mathrm{kHz}, 20 \mathrm{kHz}$, $40 \mathrm{kHz}$ and $60 \mathrm{kHz}$ ) as required. Sensors were first measured in wet-state (in PBS) for 2 time points, firstly for a baseline measurement (before sample incubation) and then after sample incubation and washing. The amplitude of the output voltage $\left(V_{\text {out }}\right)$ and the phase across the $R_{\text {ref, }}$, were recorded by a lock-in amplifier. This was used for the acquisition of frequency $(\omega)$ dependent impedimetric parameters such as impedance magnitude $(|Z|)$, capacitance $(C)$, and resistance $(R)$ based on the following equation $[20,21]$ :

$$
\begin{gathered}
V_{\text {out }} / V_{\text {in }}=R_{\text {ref }} /\left(|\mathrm{Z}|+R_{\text {ref }}\right) \\
|\mathrm{Z}|=\mathrm{R}-\mathrm{j} /(w \mathrm{C})
\end{gathered}
$$

The measurement protocol was first characterized in stage I and then applied in stage II.

\subsection{Statistical Analysis}

The number of surface-bound cells are expressed as mean \pm standard error of mean (mean \pm SEM). MATLAB ${ }^{\circledR}$ was used to calculate the sensor impedance magnitude. The baseline impedance values were used to determine outliers in accordance with our previously developed method [21]. Results were described as a percentage of change in impedance magnitude $(\% \Delta|Z|)$ before and after incubation. This was used throughout the results section, unless otherwise stated. Statistical analysis was performed by GraphPad Prism 7.0 software. Non-parametric Kruskal-Wallis one-way ANOVA followed with Dunn's multiple comparison tests were performed on data with sample sizes less than 10. For grouped samples, non-parametric two-way ANOVA with Bonferroni correction for multiple comparisons was used. $p$-values $\leq 0.05$ were considered statistically significant. 


\section{Results}

\subsection{Stage I: Specific Cell Capture on Glass and IDE Sensors Using Cell Lines}

\subsubsection{Feasibility of Cell Capture on Glass}

HLA-B*57:01 expressing cell line was incubated on glass surfaces functionalized with a 3E12 antibody or surfaces without an antibody, at 160 cells $/ \mu \mathrm{L}$ for $10 \mathrm{~min}$ at $37^{\circ} \mathrm{C}$. As observed in Figure $2 \mathrm{~A}$, a higher number of cells were captured on the surface with a 3E12 antibody compared to the surface without the antibody where very few cells were captured. To determine if this capture was selective for HLA-B*57:01, glass surfaces with or without a functionalized $3 E 12$ antibody were incubated with either HLA-B*57:01 or HLA-B*15:02 cell lines. As shown in Figure 2B, the surface functionalized with 3E12, when incubated with HLA-B*57:01 cell line, had the highest number of cells captured. This capture was significantly higher compared to other conditions with the HLA-B*15:02 cell line, or to the control surface without antibody.

A

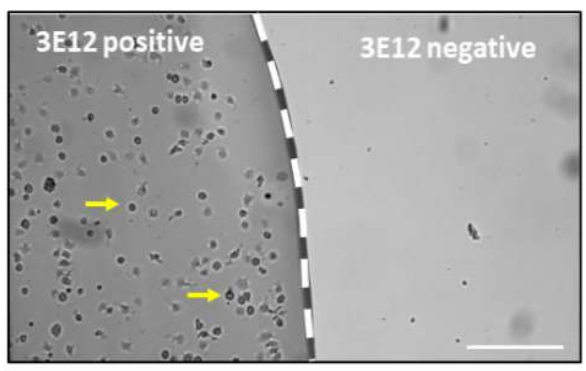

B

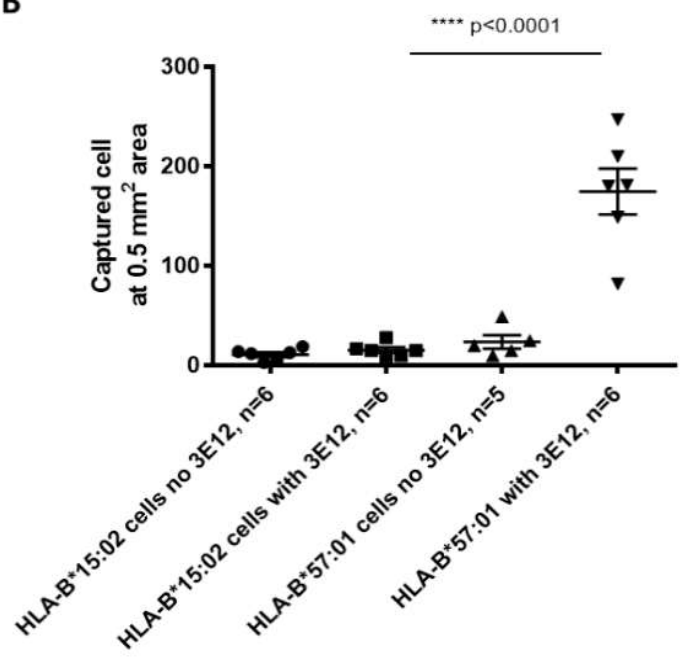

Figure 2. A 3E12 antibody capture HLA-B*57:01 expressing cell line on glass surface. (A) Glass surface showing HLA-B*57:01 positive cells captured on glass surface (yellow arrow) functionalized with a 3E12 antibody (left) and not on surface without a 3E12 antibody (right). (B) Significantly higher number of cells were captured when HLA-B*57:01 positive cells were incubated with glass surfaces functionalized with a $3 E 12$ antibody compared to other HLA groups (HLA-B*15:02) and controls within an area of $0.5 \mathrm{~mm}^{2}$ (mean \pm SEM. Bar $\left.=100 \mu \mathrm{m}\right)$.

\subsubsection{Cell Capture over Time}

The minimum time required for cell capture was evaluated. HLA-B*15:02 cell line and glass without functionalized antibodies were used as controls. Glass surfaces were incubated in HLA-B*57:01 or HLA-B ${ }^{*} 15: 02$ cell lines for 5, 10 and $20 \mathrm{~min}$ at a concentration of 160 cells/ $\mu \mathrm{L}(1 \mathrm{~mL}$ each, 160,000 cells) at $37^{\circ} \mathrm{C}$. As shown in Figure $3 \mathrm{~A}$, on an area of $0.5 \mathrm{~mm}^{2}$, the number of HLA-B*57:01 positive cells captured on the functionalized surface started to rise after incubation for $10 \mathrm{~min}$ and continued to rise after incubation for $20 \mathrm{~min}$. At $20 \mathrm{~min}$ of incubation, $314 \pm 24$ (mean \pm SEM) HLA-B*57:01 cells were captured compared to $55 \pm 9$ HLA-B*15:02 cells ( $p=0.0004)$. At these time points the number of cells captured was significantly higher compared to the HLA-B*15:02 cell line and surface without functionalized antibodies, for which the number of cells captured remained low throughout the incubation time period (Figure 3B). 
A
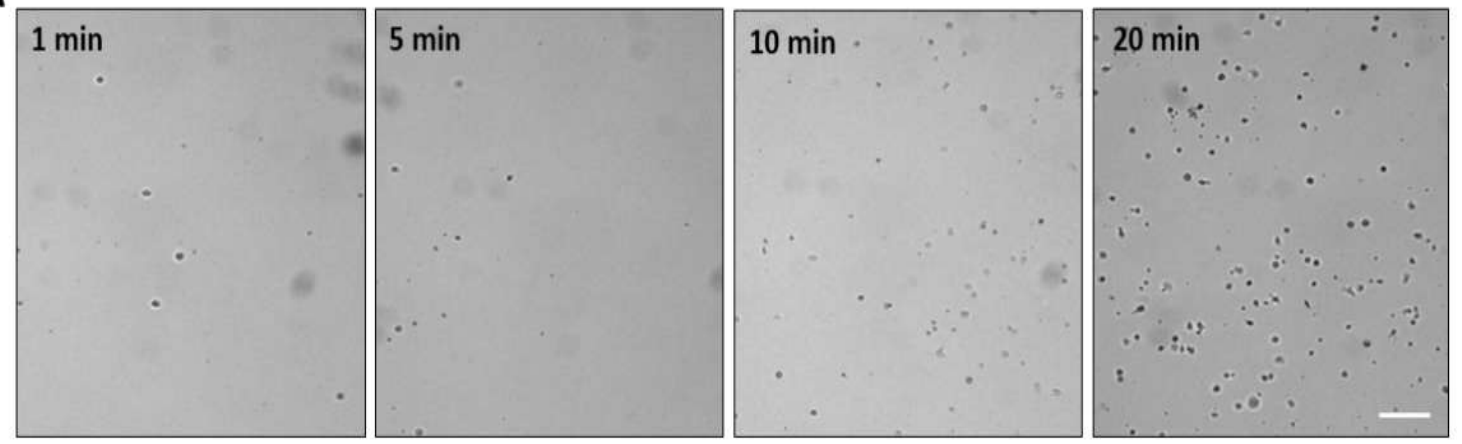

B

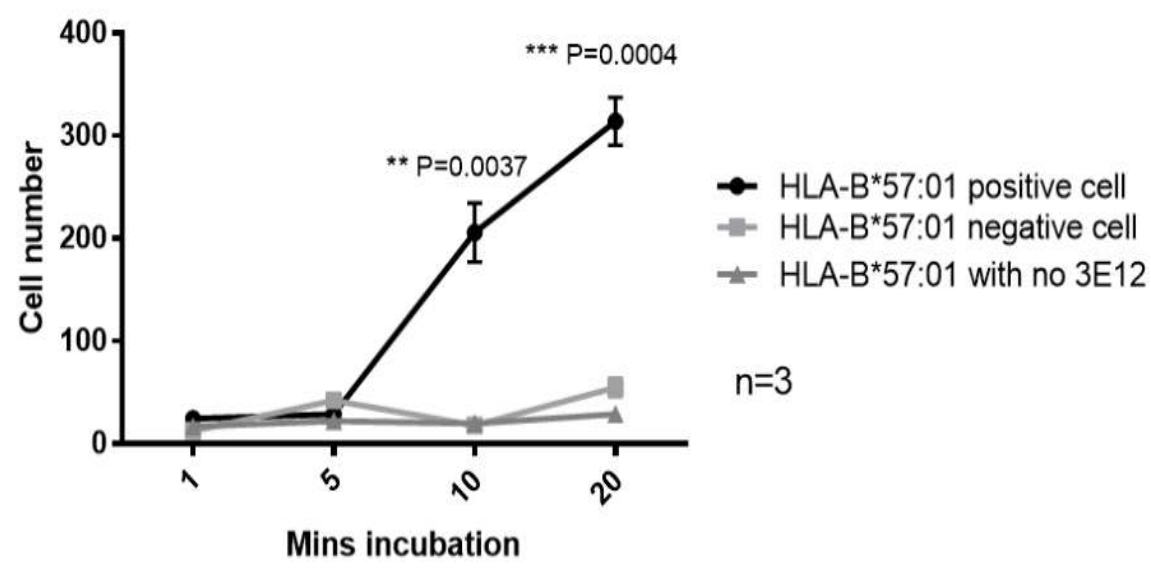

Figure 3. HLA-B*57:01 expressing cell line capture over time. (A) HLA-B*57:01 positive cells captured on a glass surface functionalized with a $3 E 12$ antibody at $1 \mathrm{~min}, 5 \mathrm{~min}, 10 \mathrm{~min}$ and $20 \mathrm{~min}$ of incubation. (B) A Significant increase in the number of HLA-B*57:01 positive cells were captured from $10 \mathrm{~min}$ of incubation compared to HLA-B*57:01 negative cells and no antibody control at $0.5 \mathrm{~mm}^{2}$ area $($ mean \pm SEM. Bar $=100 \mu \mathrm{m})$.

\subsubsection{IDE Sensor Detection of HLA-B*57:01 Cell Line}

Next, we determined whether the cell capture can be detected on the IDE sensors. 3E12 antibody was functionalized on IDE sensors and incubated with either HLA-B*57:01 expressing cells or HLA-B ${ }^{*} 15: 02$ expressing cells at $37^{\circ} \mathrm{C}$ for $20 \mathrm{~min}$, the time point with maximum capture difference (Figure 3B). Sensors incubated with HLA-B*57:01 cell lines showed a higher number of cells captured on the sensors surface compared to sensors with HLA-B*15:02 expressing cells (Figure 4A).

This capture was then subject to an electrical reading (Figure 4B) to detect difference in percentage changes in impedance magnitude $(\% \Delta|Z|)$ of the sensors with captured cells from HLA-B*57:01 positive and negative cell lines. Then four frequencies, $10 \mathrm{kHz}, 20 \mathrm{kHz}, 40 \mathrm{kHz}$ and $60 \mathrm{kHz}$ were applied for the measurement. It was observed that $10 \mathrm{kHz}$ was the optimal frequency to differentiate the sensors with captured cells. At $10 \mathrm{kHz}$, the sensors incubated with HLA-B*57:01 positive cells showed an increase in impedance magnitude. By contrast, sensors incubated with negative controls (HLA-B*15:02 and media control) generally showed decrease in impedance magnitude. 


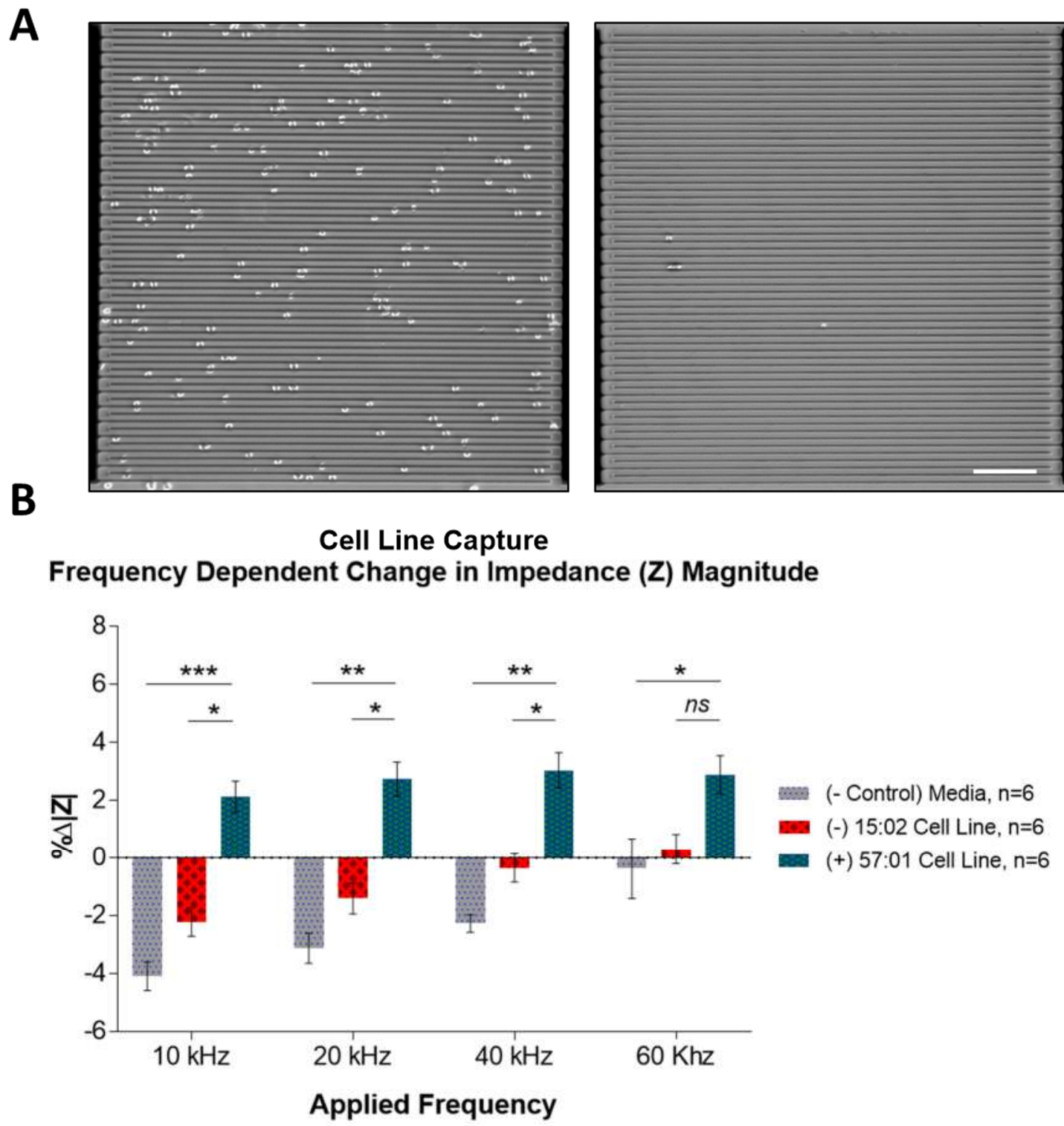

Figure 4. Interdigitated electrode (IDE) sensors detecting sensors with captured HLA-B*57:01 expressing cell line. (A) Micrograph showing HLA-B*57:01 positive cells captured on dielectric sensors functionalized with 3E12 antibody (left). Less cells were captured when HLA-B*15:02 cells were incubated on the sensor (right). (B) At applied frequency of $10 \mathrm{kHz}$ and $20 \mathrm{kHz}$, sensors showed significant impedance difference with sensors incubated HLA-B*57:01 cells compared to HLA-B*15:02 cells and blank. (mean \pm SEM. Bar $=100 \mu \mathrm{m})$.

\subsection{Stage II: Detection of Peripheral Blood Mononuclear Cells}

In this part of the study, the protocol developed in stage I was evaluated using PBMCs isolated from whole blood from donors of known HLA genotypes. Similar to the cell line experiments, glass surfaces were used followed by IDE sensors.

\subsubsection{Specific PBMC Capture on Glass}

Glass surfaces functionalized with 3E12 antibody were incubated with $1 \mathrm{~mL}$ of either HLA-B 57:01 positive or negative PBMCs $(160$ cells $/ \mu \mathrm{L})$ for $20 \mathrm{~min}$ at $37^{\circ} \mathrm{C}$. Surfaces functionalized with a 3E12 antibody had significantly greater number of captured cells when incubated with HLA-B 57 positive PBMCs (HLA-B*57 positive and HLA-B*57 negative capture: Mean \pm SEM $777 \pm 78$ and $117 \pm 13$ respectively, Figure 5). The number of cells captured with HLA-B*57-negative PBMCs are similar to 
the background and negative controls (Figure 5C). This suggested that surfaces functionalized with 3E12 antibody selectively captured PBMC expressing HLA-B*57 positive and not negative cells.
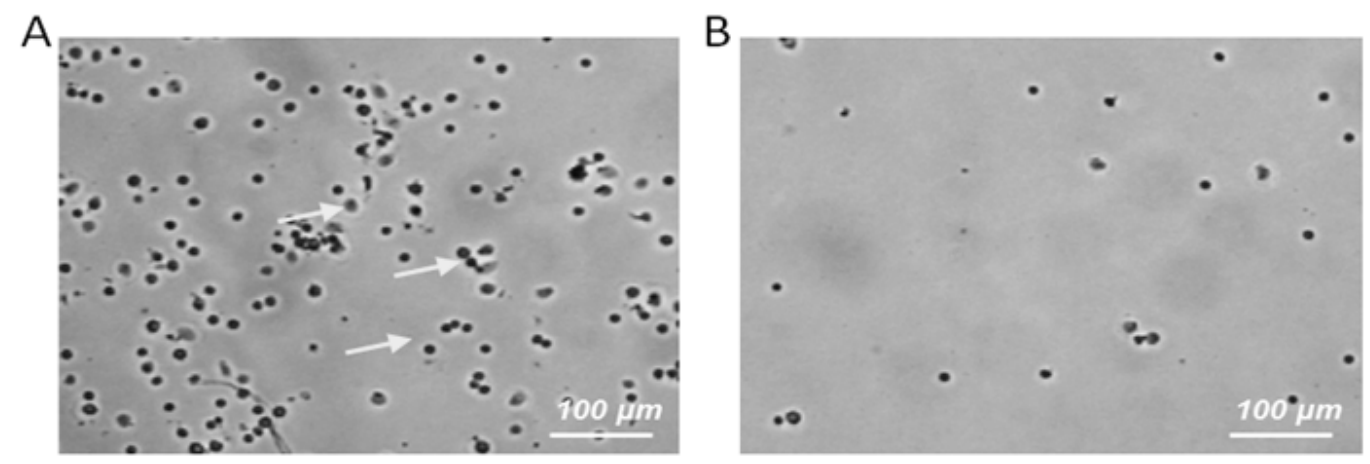

C

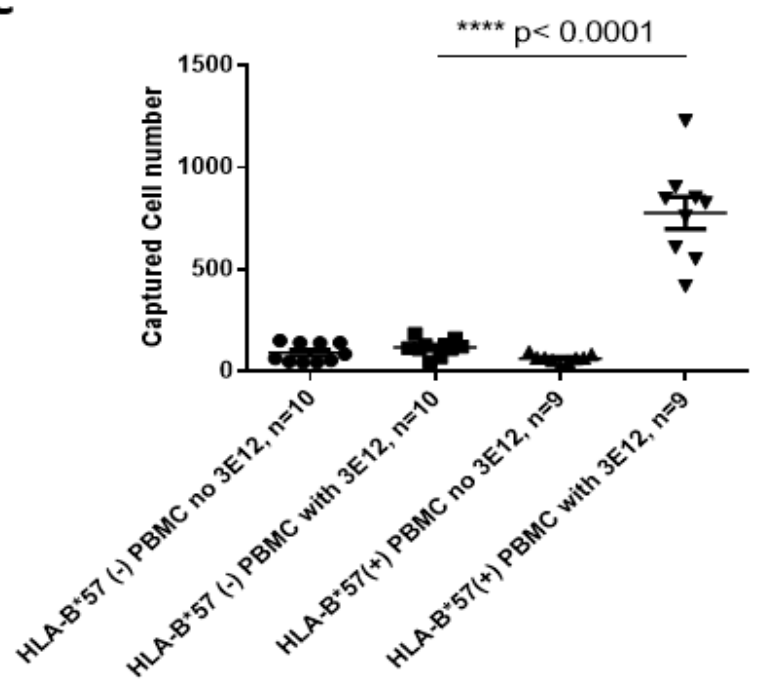

Figure 5. A 3E12 antibody capture HLA-B*57 expressing peripheral blood mononuclear cells (PBMCs) on glass surface. Glass surface showing more HLA-B*57 PBMCs captured on glass surface (white arrow) functionalized with a 3E12 antibody (A) compared to the surface without 3E12 antibody (B). (C) Significantly higher number of cells were captured when HLA-B*57 PBMCs were incubated with glass surfaces functionalized with a 3E12 antibody compared to other HLA group and controls at $0.5 \mathrm{~mm}^{2}$ area (mean \pm SEM. Bar $=100 \mu \mathrm{m}$ ).

\subsubsection{Sensor Detection of HLA-B*57:01 Positive PBMCs}

Next, we determined whether the capture of PBMCs can be detected on the IDE sensors. IDE sensors functionalized with 3E12 antibody were incubated with 10 different PBMC samples (five HLA-B*57:01 positive, five negative, $1 \mathrm{~mL}$ each at $160 \mathrm{cells} / \mu \mathrm{L}$ ) for $20 \mathrm{~min}$ at $37^{\circ} \mathrm{C}$. Sensors incubated with HLA-B*57:01 positive PBMCs captured more cells on their surfaces compared with sensors incubated with HLA-B*57 negative PBMCs and media controls (Figure 6A). This difference in capture was reflected in the impedance $(\% \Delta|\mathrm{Z}|)$ changes of sensors (Figure $6 \mathrm{~B})$. To compare the $\% \Delta|\mathrm{Z}|$ values, sensor measurements were combined into groups of HLA-B*57:01 positive, negative, and media control incubated (Figure 6C). Sensors incubated with positive PBMCs showed an average impedance magnitude change of $-4 \% \pm 1.96 \%$, which is highly distinct from the average signal of sensors incubated with negative PBMC at $0.74 \% \pm 2.4 \%(p<0.0001)$, and blank media at $-0.58 \% \pm 1.21 \%(p=0.02)$. This suggested that the IDE sensors were able to differentiate the capture of PBMCs of different HLA types. 
A

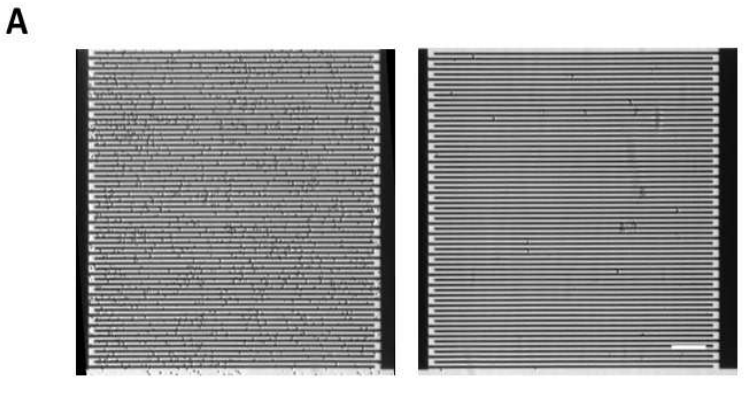

C

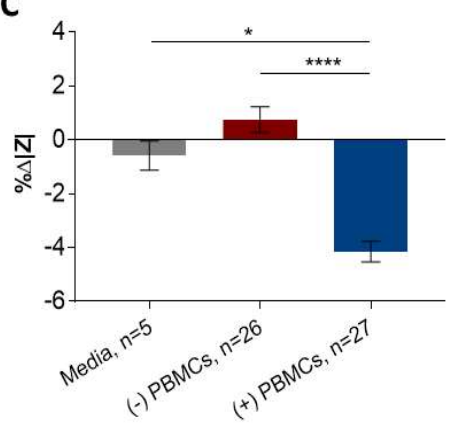

Pooled Measurements of PBMCs

\section{B}

B 51 HLA-B*57 Negative HLA-B*57 Positive

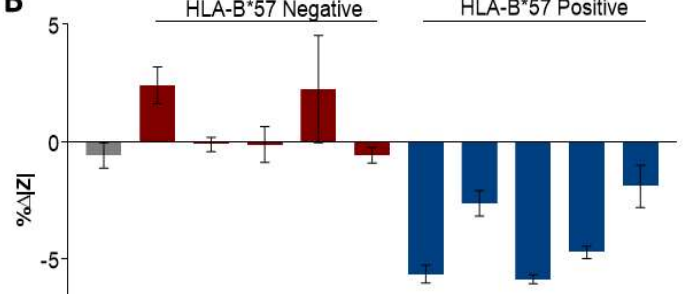

$-10$

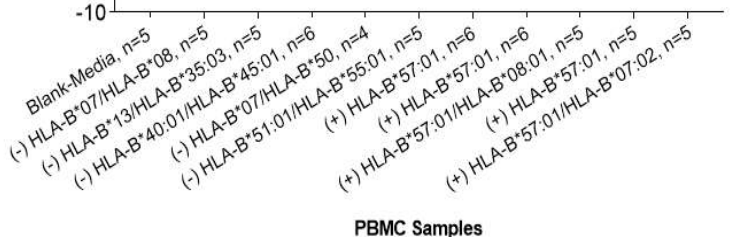

Figure 6. IDE sensors detecting sensors with captured HLA-B*57 expressing PBMCs. (A) Micrograph showing HLA-B*57:01 PBMC captured on dielectric sensors functionalized with a 3E12 antibody (left). Less cells were captured when non-HLA-B*57:01 were incubated on the sensor (right). (B) At applied frequency of $10 \mathrm{kHz}$, sensors showed significant impedance difference with sensors incubated HLA-B*57:01 PBMCs cells compared to non-HLA-B*57:01 PBMCs. (C) Sensor measurements were combined into groups of HLA-B*57:01 positive, HLA-B*57:01 negative, and media control incubated (mean \pm SEM. Bar $=100 \mu \mathrm{m})$.

\section{Discussion}

This study presented a novel way of HLA-B*57:01 testing through antibody capture of HLA-B*57:01 expressing cells and electrical detection by IDE sensors. Results were obtained in 20 min of cell incubation at $37^{\circ} \mathrm{C}$.

The first stage of the study involved proof-of-concept and optimisation experiments. The feasibility and the characteristics of cells captured were first established. This was achieved through a series of proof-of-concept experiments conducted on silicon-dioxide (glass) surfaces using HLA-B*57:01 expressing and non-expressing cell lines. The glass slides that were used as the surface have similarities with the IDE sensor and its conditions can be readily manipulated when required. As seen in Figure 2, glass surfaces functionalized with a $3 \mathrm{E} 12$ antibody was able to capture whole cells expressing HLA-B*57:01 and did not capture HLA-B*57:01 negative cells lines after incubating for $10 \mathrm{~min}$ to $20 \mathrm{~min}$.

The cell capture condition was then applied to functionalized IDE sensors where captured cells underwent electrical detection to characterize its impedance magnitude, a method of detection that is suitable for adaptation into a point-of-care device. It was observed that the capture of HLA-B*57:01 cells lines resulted in an increase of the sensors' impedance magnitude. In contrast, incubation with HLA-B*57:01 negative cells line and media resulted in a decrease of the sensors' impedance magnitude. This suggested that cell capturing by the IDE sensor could be detected by determining the change in impedance. The experimental conditions established in this part of the study formed the basis for stage II where they were extended to evaluate PBMCs isolated from human blood samples.

In stage II, glass surface functionalized with 3E12 showed similar capture characteristics of PBMCs to cell lines in stage I. A higher number of HLA-B*57 positive PBMCs was captured compared to HLA-B*57 and B*57 negative PBMCs. The PBMC samples were then tested on IDE sensors 
functionalized with a 3E12 antibody. It was found that these sensors were able to capture more HLA-B*57:01 positive PBMCs compared to HLA-B*57 negative samples, resulting in differences in impedance change. It was noted that the characteristic of change in impedance using PBMCs was different from that observed using cell lines. This could be due to the difference in the cell types of the samples. PBMC contains many different types of white cells, whereas the cell line used is derived from one cell type within PBMC (B-cell), which makes up of less than $10 \%$ of all the cell types $[23,24]$. Sample dependent differences in sensitivity in impedance sensors have been observed previously [25]. Furthermore, cell lines are generally actively dividing while PBMCs are not. This might result in a difference in ionic composition of the media between the cell lines and PBMCs, resulting in different characteristics of impedance change.

Since impedance-based detection detects the changes of conductivity resulting from the differences between electrical property of the target and its medium [26], it is important to perform characterisation for the specific type of sample used. Despite the difference in the pattern of change, the frequency of 10 $\mathrm{kHz}$ allowed a highly specific detection of capture cells across both sample types, without the use of additional signal labelling or amplification strategies used in other impedance-based HLA-B detection previously reported [20].

Our approach has its limitations. In this study, pre-treated blood samples (PBMCs) were used to characterize cell capture on the sensor. As complex pre-treatment of blood is not be ideal for point-of-care setting, future work to characterize the sensor using untreated whole blood samples of different HLA groups are needed. To bring this work closer towards point-of-care settings, further work on the essential sensor's performance will be needed. These will include establishing the limit of detection to establish an optimal detectable cell capture range, sensor stability, sensitivity and reproducibility under different conditions and environmental factors.

Though the mAb 3E12 is specific to the B17 group it does not discriminate between the subtypes within this group, which include HLA-B*57:01 or HLA-B*58:01 [11]. The carrier rate of HLA-B*57:01 varies across ethnic populations, from less than $1 \%$ in African population to $20 \%$ in parts of India [11]. In comparison, HLA-B*58:01 is mostly found in Asian subpopulations, particularly in individuals of Korean, Han Chinese, or Thai descent with carrier rate that varies across populations, from less than $6 \%$ in the Korean population to $17 \%$ in parts of China [27-30]. Therefore, although our HLA-B*57 sensing platform does not uniquely detect HLA-B*57:01, it can be used to exclude most individuals from costly HLA testing and allow them to receive abacavir with confidence. In other words, only patients who test positive would need to undergo gold standard HLA-B*57:01 genotyping and withhold prescription of abacavir until this result is known. This practice would be able to reduce the overall cost and time constraints of screening. Furthermore, HLA-B*58:01 is associated with hypersensitivity to allopurinol, which is commonly used to treat hyperuricaemia and recurrent gout [31,32]. Therefore, future studies could explore the potential application of the IDE sensors for pre-treatment screening prior to allopurinol use.

\section{Conclusions}

We have developed an IDE sensor platform for label-free HLA-B*57:01 screening for the prevention of abacavir hypersensitivity. This was done using the 3E12 monoclonal antibody -functionalized IDE sensors. Specific HLA-B*57:01 PBMC capture was attained in just $20 \mathrm{~min}$, with a significant change in the impedance magnitude detected by the sensors. With further development, this platform can be adapted to a point-of-care system which can facilitate HLA testing for ADR from abacavir use in HIV treatment.

Author Contributions: Conceptualization, J.C., G.V.S., M.T., P.K., E.S., J.M., L.K., and L.C.; methodology, P.K., E.S., J.C., G.V.S., L.K., S.M.U., and L.C.; software, D.H.H.; validation, J.C., G.V.S., L.K., C.D.A., and L.C.; formal analysis, J.C., G.V.S. and L.C.; investigation, J.C., G.V.S., L.C.; resources, J.C. and L.K.; data curation, J.C., L.C. and G.V.S.; writing-original draft preparation, J.C.; writing-review and editing, All authors.; visualization, J.C., G.V.S., and L.C.; supervision, P.K., J.M. and E.S.; project administration, J.C.; funding acquisition, P.K. 
Funding: This work was supported in part by the Australian Research Council (DP140101967) and the Royal Melbourne Hospital Neuroscience Foundation. G.V.S. was supported by the Indonesian Endowment Fund for Education. E.S. thanks the generous support of Sue and Leigh Clifford in establishing the Chair in Neural Engineering. P.K. is supported by the Medical Research Future Fund Practitioner Fellowship $(1,136,427)$. J.M. was supported by an Australian National Health \& Medical Research Council Program Grant APP1113293 and Australian Research Council Discovery Grant ARC Discovery Grant (DP170103822).

Acknowledgments: This work was performed in part at the Melbourne Centre for Nanofabrication (MCN) in the Victorian Node of the Australian National Fabrication Facility (ANFF). We thank the Australian Red Cross Blood Service and Dr Nicole Mifsud, Monash University, for providing the PMBCs.

Conflicts of Interest: The authors declare no conflicts of interest.

\section{References}

1. Kass-Bartelmes, B.L. Agency for Healthcare Research and Quality. In Reducing and Preventing Adverse Drug Events to Decrease Hospital Costs [Electronic Resource]; U.S. Department of Health and Human Services, Agency for Healthcare Research and Quality: Rockville, MD, USA, 2001.

2. Svensson, C.K.; Cowen, E.W.; Gaspari, A.A. Cutaneous drug reactions. Pharm. Rev. 2001, 53, 357-379. [PubMed]

3. Robinson, J.; Halliwell, J.A.; Hayhurst, J.D.; Flicek, P.; Parham, P.; Marsh, S.G. The IPD and IMGT/HLA database: Allele variant databases. Nucleic Acids Res. 2015, 43, D423-D431. [CrossRef] [PubMed]

4. Hetherington, S.; Hughes, A.R.; Mosteller, M.; Shortino, D.; Baker, K.L.; Spreen, W.; Lai, E.; Davies, K.; Handley, A.; Dow, D.J.; et al. Genetic variations in HLA-B region and hypersensitivity reactions to abacavir. Lancet 2002, 359, 1121-1122. [CrossRef]

5. Hetherington, S.; McGuirk, S.; Powell, G.; Cutrell, A.; Naderer, O.; Spreen, B.; Lafon, S.; Pearce, G.; Steel, H. Hypersensitivity reactions during therapy with the nucleoside reverse transcriptase inhibitor abacavir. Clin. Ther. 2001, 23, 1603-1614. [CrossRef]

6. Mallal, S.; Nolan, D.; Witt, C.; Masel, G.; Martin, A.M.; Moore, C.; Sayer, D.; Castley, A.; Mamotte, C.; Maxwell, D.; et al. Association between presence of HLA-B*5701, HLA-DR7, and HLA-DQ3 and hypersensitivity to HIV-1 reverse-transcriptase inhibitor abacavir. Lancet 2002, 359, 727-732. [CrossRef]

7. Martin, A.M.; Nolan, D.; Gaudieri, S.; Almeida, C.A.; Nolan, R.; James, I.; Carvalho, F.; Phillips, E.; Christiansen, F.T.; Purcell, A.W.; et al. Predisposition to abacavir hypersensitivity conferred by HLA-B*5701 and a haplotypic Hsp70-Hom variant. Proc. Natl. Acad. Sci. USA 2004, 101, 4180-4185. [CrossRef] [PubMed]

8. Chessman, D.; Kostenko, L.; Lethborg, T.; Purcell, A.W.; Williamson, N.A.; Chen, Z.; Kjer-Nielsen, L.; Mifsud, N.A.; Tait, B.D.; Holdsworth, R.; et al. Human leukocyte antigen class I-restricted activation of CD8+ $\mathrm{T}$ cells provides the immunogenetic basis of a systemic drug hypersensitivity. Immunity 2008, 28, 822-832. [CrossRef]

9. Illing, P.T.; Vivian, J.P.; Dudek, N.L.; Kostenko, L.; Chen, Z.; Bharadwaj, M.; Miles, J.J.; Kjer-Nielsen, L.; Gras, S.; Williamson, N.A.; et al. Immune self-reactivity triggered by drug-modified HLA-peptide repertoire. Nature 2012, 486, 554. [CrossRef]

10. Mallal, S.; Phillips, E.; Carosi, G.; Molina, J.M.; Workman, C.; Tomazic, J.; Jagel-Guedes, E.; Rugina, S.; Kozyrev, O.; Cid, J.F.; et al. HLA-B*5701 screening for hypersensitivity to abacavir. N. Engl. J. Med. 2008, 358, 568-579. [CrossRef]

11. Nolan, D.; Gaudieri, S.; Mallal, S. Pharmacogenetics: A practical role in predicting antiretroviral drug toxicity? J. HIV Ther. 2003, 8, 36-41.

12. Waters, L.J.; Mandalia, S.; Gazzard, B.; Nelson, M. Prospective HLA-B ${ }^{* 5701}$ screening and abacavir hypersensitivity: A single centre experience. Aids 2007, 21, 2533-2534. [CrossRef] [PubMed]

13. Zucman, D.; Truchis, P.; Majerholc, C.; Stegman, S.; Caillat-Zucman, S. Prospective screening for human leukocyte Antigen-B*5701 avoids abacavir hypersensitivity reaction in the ethnically mixed French HIV population. J. Acquir. Immune. Defic. Syndr. 2007, 45, 1-3. [CrossRef] [PubMed]

14. Cascella, R.; Strafella, C.; Ragazzo, M.; Zampatti, S.; Borgiani, P.; Gambardella, S.; Pirazzoli, A.; Novelli, G.; Giardina, E. Direct PCR: A new pharmacogenetic approach for the inexpensive testing of HLA-B*57:01. Pharm. J. 2015, 15, 196-200. [CrossRef] [PubMed]

15. Hammond, E.; Mamotte, C.; Nolan, D.; Mallal, S. HLA-B*5701 typing: Evaluation of an allele-specific polymerase chain reaction melting assay. Tissue Antigens 2007, 70, 58-61. [CrossRef] [PubMed] 
16. Puangpetch, A.; Koomdee, N.; Chamnanphol, M.; Jantararoungtong, T.; Santon, S.; Prommas, S.; Hongkaew, Y.; Sukasem, C. HLA-B allele and haplotype diversity among Thai patients identified by PCR-SSOP: Evidence for high risk of drug-induced hypersensitivity. Front. Genet. 2014, 5, 478. [CrossRef] [PubMed]

17. Kostenko, L.; Kjer-Nielsen, L.; Nicholson, I.; Hudson, F.; Lucas, A.; Foley, B.; Chen, K.; Lynch, K.; Nguyen, J.; $\mathrm{Wu}, \mathrm{A} . \mathrm{H}$; et al. Rapid screening for the detection of HLA-B57 and HLA-B58 in prevention of drug hypersensitivity. Tissue Antigens 2011, 78, 11-20. [CrossRef] [PubMed]

18. Abeyrathne, C.D.; Huynh, D.H.; Lee, T.T.; Nguyen, T.C.; Nasr, B.; Chana, G.; Skafidas, E. GFAP Antibody Detection Using Interdigital Coplanar Waveguide Immunosensor. IEEE Sens. J. 2016, 16, $2898-2905$. [CrossRef]

19. Abeyrathne, C.D.; Huynh, D.H.; McIntire, T.W.; Nguyen, T.C.; Nasr, B.; Zantomio, D.; Chana, G.; Abbott, I.; Choong, P.; Catton, M.; et al. Lab on a chip sensor for rapid detection and antibiotic resistance determination of Staphylococcus aureus. Analyst 2016, 141, 1922-1929. [CrossRef]

20. Soraya, G.V.; Chan, J.; Nguyen, T.C.; Huynh, D.H.; Abeyrathne, C.D.; Chana, G.; Todaro, M.; Skafidas, E.; Kwan, P. An interdigitated electrode biosensor platform for rapid HLA-B*15:02 genotyping for prevention of drug hypersensitivity. Biosens. Bioelectron. 2018, 111, 174-183. [CrossRef]

21. Soraya, G.V.; Nguyen, T.C.; Abeyrathne, C.D.; Huynh, D.H.; Chan, J.; Nguyen, P.D.; Nasr, B.; Chana, G.; Kwan, P.; Skafidas, E. A Label-Free, Quantitative Fecal Hemoglobin Detection Platform for Colorectal Cancer Screening. Biosensors (Basel) 2017, 7, 19. [CrossRef]

22. Wang, L.; Veselinovic, M.; Yang, L.; Geiss, B.J.; Dandy, D.S.; Chen, T. A sensitive DNA capacitive biosensor using interdigitated electrodes. Biosens. Bioelectron. 2017, 87, 646-653. [CrossRef] [PubMed]

23. Glassman, A.B.; Bennett, C.E. B and T lymphocytes: Methodology and normal ranges. Ann. Clin. Lab. Sci. 1977, 7, 519-523. [PubMed]

24. Neitzel, H. A routine method for the establishment of permanent growing lymphoblastoid cell lines. Hum. Genet. 1986, 73, 320-326. [CrossRef] [PubMed]

25. Radke, S.M.; Alocilja, E.C. A high density microelectrode array biosensor for detection of E. coli O157:H7. Biosens. Bioelectron. 2005, 20, 1662-1667. [CrossRef] [PubMed]

26. Sabounchi, P.; Morales, A.M.; Ponce, P.; Lee, L.P.; Simmons, B.A.; Davalos, R.V. Sample concentration and impedance detection on a microfluidic polymer chip. Biomed. Microdevices 2008, 10, 661-670. [CrossRef] [PubMed]

27. Allelefrequencies net. Database for immune gene frequencies in worldwide populations. Available online: http://www.allelefrequencies.net (accessed on 1 October 2018).

28. Hershfield, M.S.; Callaghan, J.T.; Tassaneeyakul, W.; Mushiroda, T.; Thorn, C.F.; Klein, T.E.; Lee, M.T. Clinical Pharmacogenetics Implementation Consortium guidelines for human leukocyte antigen-B genotype and allopurinol dosing. Clin. Pharmacol. Ther. 2013, 93, 153-158. [CrossRef] [PubMed]

29. Khanna, D.; Fitzgerald, J.D.; Khanna, P.P.; Bae, S.; Singh, M.K.; Neogi, T.; Pillinger, M.H.; Merill, J.; Lee, S.; Prakash, S.; et al. American College of Rheumatology guidelines for management of gout. Part 1: Systematic nonpharmacologic and pharmacologic therapeutic approaches to hyperuricemia. Arthritis Care Res. (Hoboken) 2012, 64, 1431-1446. [CrossRef]

30. Saito, Y.; Stamp, L.K.; Caudle, K.E.; Hershfield, M.S.; McDonagh, E.M.; Callaghan, J.T.; Tassaneeyakul, W.; Mushiroda, T.; Kamatani, N.; Goldspiel, B.R.; et al. Clinical Pharmacogenetics Implementation Consortium (CPIC) guidelines for human leukocyte antigen B (HLA-B) genotype and allopurinol dosing: 2015 update. Clin. Pharmacol. Ther. 2016, 99, 36-37. [CrossRef]

31. Hung, S.I.; Chung, W.H.; Liou, L.B.; Chu, C.C.; Lin, M.; Huang, H.P.; Lin, Y.L.; Lan, J.L.; Yang, L.C.; Hong, H.S.; et al. HLA-B*5801 Allele as a genetic marker for severe cutaneous adverse reactions caused by allopurinol. Proc. Natl. Acad. Sci. USA 2005, 102, 4134-4139. [CrossRef]

32. Lonjou, C.; Borot, N.; Sekula, P.; Ledger, N.; Thomas, L.; Halevy, S.; Naldi, L.; Bouwes-Bavinck, J.N.; Sidoroff, A.; de Toma, C.; et al. A European study of HLA-B in Stevens-Johnson syndrome and toxic epidermal necrolysis related to five high-risk drugs. Pharm. Genom. 2008, 18, 99-107. [CrossRef]

(C) 2019 by the authors. Licensee MDPI, Basel, Switzerland. This article is an open access article distributed under the terms and conditions of the Creative Commons Attribution (CC BY) license (http://creativecommons.org/licenses/by/4.0/). 